\section{Interações públicas, censura privada: o caso do Facebook}

\section{Public interactions, private censorship: the case of Facebook}

\author{
Sergio Amadeu da Silveira \\ Professor, Centro de Engenharia, Modelagem e \\ Ciências Sociais Aplicadas/Universidade Federal do ABC. \\ Avenida dos Estados, 5001 \\ 09210-580 - Santo André - SP - Brasil \\ sergio.amadeu@ufabc.edu.br
}

Recebido para publicação em setembro de 2014.

Aprovado para publicação em maio de 2015.

http://dx.doi.org/10.1590/S0104-59702015000500006
SILVEIRA, Sergio Amadeu da. Interações públicas, censura privada: o caso do Facebook. História, Ciências, SaúdeManguinhos, Rio de Janeiro, v.22, supl., dez. 2015, p.1637-1651.

\section{Resumo}

O Facebook é apresentado como uma plataforma de relacionamento social on-line transnacional em que ocorrem debates e interações públicas. $\mathrm{O}$ texto traz um levantamento sobre o controle privado das expressões culturais e políticas realizadas pelos gestores da plataforma, que pode ser definido como censura privada. Casos de remoção de conteúdo são apresentados, e são expostas as políticas de controle do Facebook. O texto mostra ainda que as regras do Facebook trazem fortes componentes discricionários e uma estética que pode ser apresentada como um tipo de biopolítica da sociedade informacional.

Palavras-chave: Facebook; censura privada; rede social; biopolítica.

\section{Abstract}

Facebook is examined as a transnational online social networking platform where public discussions and interactions take place. The study surveys the private control of cultural and political expressions exercised by the platform's managers, which can be defined as private censorship. Cases of removal of content are presented and Facebook's political control policies discussed. The article also shows how Facebook rules display highly discretionary components and an aesthetic that can be portrayed as a kind of biopolitics of the information-age society.

Keywords: Facebook; private censorship; social network; biopolitics. 
$\mathrm{E}_{\mathrm{s}}$ ste texto apresenta a investigação sobre dez casos de bloqueio ou remoção de postagens

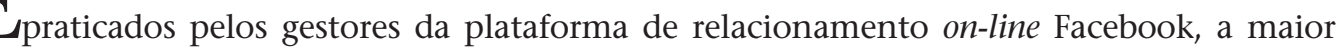
rede social construída na internet. A comparação do conteúdo e do formato dos conteúdos removidos com a "Política de uso de dados" (Política de uso..., s.d.) e com os "Padrões da comunidade do Facebook" (Padrões..., s.d.) confirmou que, em três dos casos, a remoção da postagem fugia das regras e indicava um elevado grau de arbitrariedade. Os outros sete casos de bloqueio tinham como provável motivação a proibição de imagens de nudez.

Aqui não serão apresentados o detalhamento da pesquisa nem a descrição dos casos analisados. O objetivo deste artigo é descortinar o cenário sociotécnico que permite o surgimento e a manutenção de uma censura privada sobre os cidadãos que vivem em um país cujo ordenamento jurídico assegura liberdades fundamentais, bem maiores e mais bem delimitadas do que as existentes no Facebook. A enorme adesão de pessoas de diversas nacionalidades e classes sociais às redes sociais, em particular ao Facebook, trouxe novos desafios para a democracia e para o debate sobre a legitimidade e o alcance de direitos antes consolidados, tais como a liberdade de expressão e a privacidade.

As redes de relacionamento social construídas na internet são componentes importantes daquilo que a teoria política tem chamado de esfera pública. Pessoas comuns, utilizando linguagens cotidianas, trocam opiniões e constroem nessas redes suas visões e discursos também sobre o poder político e sobre os diversos fatos que afetam suas vidas. Desse modo, partindo da perspectiva habermasiana, as redes sociais na internet poderiam ser facilmente vistas como cenários da manifestação e existência do "mundo da vida", embora não seja difícil constatar empiricamente que nem todas as conversações são necessariamente "voltadas ao entendimento" (Habermas, 1997, p.92).

A internet foi considerada por Yochai Benkler (2006, p.212) como o terreno de uma esfera pública interconectada. Tal ponto de vista pode estar em conformidade com uma das visões mais recentes de Habermas (1997, p.107) sobre a esfera pública formadora de "uma estrutura intermediária que faz a mediação entre o sistema político, de um lado, e os setores privados do mundo da vida e sistemas de ação especializados em termos de funções, de outro lado". A emergência das chamadas redes sociais on-line nos primeiros anos do século XXI fortalece essa perspectiva. No interior da internet, as redes sociais se estruturaram como pontos de encontro mais visíveis do ciberespaço, e seus usos efetivos equivalem à junção do que Habermas (1997, p.107) definiu como três tipos de esferas públicas mais ou menos especializadas, existentes em sociedades complexas: "esfera pública episódica (bares, cafés, encontros de rua), esfera pública da presença organizada (encontros de pais, público que frequenta o teatro, concertos de rock, reuniões de partidos ou congressos de igrejas) e esfera pública abstrata, produzida pela mídia (leitores, ouvintes, espectadores singulares e espalhados globalmente)".

Em uma mesma rede social, as pessoas conectadas podem conversar como ocorre em uma mesa de bar, podem torcer e apoiar uma causa, podem comentar uma novela ou um jogo de futebol, podem articular pessoas como em uma reunião, podem expressar seu afeto ou seu ódio a alguém ou a uma proposição, imagem ou comentário. Com a popularização das redes sociais, elas passam a conformar um espaço de formação da opinião pública enredada, observação cada vez mais difícil de refutar. Segundo a pesquisa TIC Domicílios e Usuários 2013, realizada pelo Comitê Gestor da Internet, 77\% dos brasileiros conectados participam de 
redes sociais, sendo que esse número já atinge 73\% dos internautas residentes em áreas rurais. É bastante curioso que o número de usuários de redes sociais no Brasil continue a superar, em 2013, o dos usuários de e-mail, a saber, 72\% da população conectada (Cetic-CGI, 2013).

A grande relevância das redes sociais on-line na atualidade é evidente, principalmente quando o Facebook e o YouTube passam a integrar, junto com o mecanismo de busca Google, a lista dos três sites mais acessados do mundo (Alexa, s.d.). No Brasil, em março de 2013, o Facebook conquista 67 milhões de usuários, representando 4,6\% dos visitantes globais da rede de relacionamento. O nanoblogger Twitter, no mesmo período, atingiu aproximadamente duzentos milhões de usuários ativos e quatrocentos milhões de tuítes diários (Em dois anos..., 20 mar. 2013).

Torna-se fundamental problematizar os limites democráticos e o caráter biopolítico dessas redes sociais, inicialmente definidas como uma esfera pública, mais ou menos especializadas e, simultaneamente, organizadas como plataformas privadas, em contraposição à abertura das redes digitais distribuídas, ou seja, aos amplos espaços da internet. Nessa problematização, aparece com muita intensidade o problema do estatuto privado de uma plataforma que exerce o papel de um local virtual público de debates e articulações. Essa condição privada é também comercial e transnacional, o que traz mais dificuldades para o debate da forte presença da exceção como regra quando o objetivo é identificar as motivações do bloqueio e da remoção de conteúdos postados pelos cidadãos-usuários na maior das redes sociais, o Facebook.

Para melhor expor o problema, é importante recorrer à imagem de um campeonato nacional de futebol. Nele, jogos são disputados em estádios públicos e privados. A presença da torcida do time da casa é mais relevante para a disputa do que a propriedade do estádio. Todavia, em nenhum momento o estatuto privado do estádio pode interferir na disputa, não pode violar as regras do jogo. Isso não tem ocorrido nas redes sociais, em especial, no Facebook. Vamos primeiro mostrar casos de interferência política e cultural que ocorreram na rede social. Em seguida, vamos problematizar o fenômeno do ponto de vista de uma biopolítica de modulação, bem como sob a perspectiva democrática.

\section{Sistematizando os casos de remoção de conteúdo}

O Facebook, como uma rede de relacionamento social transnacional, está submetido a diversas legislações nacionais, sendo por vezes obrigado a praticar a remoção de conteúdos de seus usuários por determinação dos Estados, democráticos ou ditatoriais. O que poderia passar despercebido é que o Facebook também pratica remoção de conteúdos sem ser obrigado por nenhum governo. A plataforma de relacionamento social possui regras próprias de remoção de postagens ou publicação de textos, fotos e vídeos.

A revista The Economist de 28 de agosto de 2014 trouxe um artigo denominado "Arbitrary and capricious", em que relata o nível de arbitrariedade praticado pelos gestores do Facebook na aplicação das regras de remoção de conteúdos. A matéria relata que seu autor foi banido do Facebook por 24 horas depois de ter publicado uma foto com os objetos bem longe da câmera, em que pessoas estavam nuas, todas de costas, em uma praia. Logo em seguida, o jornalista expõe a imagem da notificação que enviou para o Facebook denunciando uma página intitulada "Morte a Israel!". O print screen com a resposta dos gestores da rede social 
também é publicada na matéria: a equipe do Facebook afirmou que a página não violava nenhuma das regras de convivência da plataforma. Uma imagem de pessoas nuas, distantes, sem nenhuma conotação de pornografia, foi considerada mais grave do que um chamamento ao ódio religioso ou político.

Seria o comportamento relatado pela The Economist um fato isolado? O levantamento aqui realizado indica que não. Em 4 de agosto de 2013, foram realizadas buscas da expressão "Facebook censura" no Google, em língua portuguesa. Para minimizar o fato de o Google apresentar resultados distintos a depender de quem faz a busca, com o objetivo de personalizar as respostas, foram utilizados dois computadores e dois endereços IPs diferentes. O retorno do mecanismo de busca para o primeiro computador gerou 18.100.000 ocorrências, em 0,25 segundos, e 18.300.000, em 0,35 segundos, no segundo. Cruzando as buscas, eliminando conteúdos e comentários genéricos sobre a censura, foram ordenados os dez casos com maior repercussão de censura praticada pelo Facebook, conforme os critérios de relevância definidos pelo maior site de busca do mundo. Os casos são os seguintes:

Caso 1: Post do jornal Folha de S.Paulo com imagem de manifestantes nus na Câmara Municipal de Porto Alegre (19 jul. 2013). A publicação feita na página oficial no Facebook do jornal Folha de S.Paulo que trazia uma imagem de manifestantes nus na Câmara Municipal de Porto Alegre foi apagada pela rede social. Além disso, o jornalista responsável pela postagem teve a conta na rede social suspensa por 24 horas.

Caso 2: Ilustração de Alexandre de Maio para a revista Carta Capital que mostra mulher nua sendo revistada (25 jul. 2013). O desenho que ilustrava uma reportagem sobre revistas íntimas em mulheres e crianças para entrar em presídios foi apagado da página da revista.

Caso 3: "Dilma Bolada", perfil falso da presidente Dilma Rousseff (Partido dos Trabalhadores, PT), e a piada sobre o senador Aécio Neves (Partido da Social Democracia Brasileira, PSDBMG) (29 maio 2013). O perfil da personagem "Dilma Bolada", criado por Jeferson Monteiro, é famoso pelas sátiras que realiza com os assuntos que envolvem a política no Brasil. Um texto relatando que o senador Aécio Neves (PSDB) mentia foi apagado do Facebook sem autorização do criador da página (Bruno, 29 maio 2013).

Caso 4: Página do presidente do PT do Paraná apagada por críticas a político do PSDB (9 jul. 2013). O deputado e presidente do PT-PR, Enio Verri, publicou posts de crítica ao governador Beto Richa (PSDB) sobre o caso da "sogra fantasma". As postagens eram acompanhadas de links que direcionavam o internauta a reportagens da Gazeta do Povo e RPC/TV. O Facebook tirou a página de Verri do ar.

Caso 5: O jornal suíço Tribune de Genève (19 out. 2012) foi bloqueado após ter publicado um artigo ilustrado com a imagem do quadro A origem do mundo, do pintor francês Gustave Coubert. A utilização do quadro de 1886, para ilustrar um artigo sobre operação plástica para diminuir os pequenos lábios da vagina, gerou o bloqueio da conta do jornal suíço no Facebook.

Caso 6: Grupo feminista ucraniano Femen (25 jun. 2013). Fundado em 2008, o grupo feminista Femen tornou-se conhecido por seus atos de protesto, tendo como marca principal os seios à mostra. É comum as postagens do movimento no Facebook serem 
retiradas do ar. Em junho de 2013, duas páginas do movimento foram bloqueadas e, horas depois, uma delas voltou ao ar, mas com a imagem dos seios de suas integrantes borrada. Caso 7: Fotos da "Marcha das Vadias", ocorrida em várias cidades do Brasil nos dias 26 e 27 de maio de 2012. A "Marcha das Vadias" tem como objetivo protestar contra a crença de que as mulheres vítimas de estupro teriam provocado a violência por seu comportamento. No evento, algumas mulheres deixam os seios à mostra e publicam fotos no Facebook. Diversos usuários que postaram conteúdos da Marcha na rede social tiveram a conta bloqueada.

Caso 8: Foto da tatuagem de uma mulher que passou por uma mastectomia dupla (13 fev. 2013). O proprietário de um estúdio de tatuadores canadense publicou a imagem de um livro que mostrava uma mulher com o peito tatuado após passar por uma mastectomia dupla. O Facebook retirou a imagem do ar, mas em protesto o empresário publicou novamente a foto e conseguiu que fosse difundida na rede.

Caso 9: Bicicletada em homenagem a Nelson Rabello, em Curitiba (19 nov. 2012). Nelson Rabello é uma figura conhecida em Curitiba como Oilman, ele costuma passar óleo bronzeador no corpo e andar de bicicleta pela cidade usando sunga e tênis. Ocorreu uma bicicletada em homenagem a ele, e os participantes se vestiram como o personagem. A imagem do evento publicada por um jornalista em sua página no Facebook foi deletada.

Caso 10: Charges com o profeta Maomé nu, publicadas pelo semanário francês Charlie Hebdo, foram deletadas da página da revista francesa Le Point (20 set. 2012). Sob o título "Por que Charlie Hebdo brinca com fogo?", a revista Le Point postou em sua página do Facebook uma das polêmicas charges em que Maomé aparece nu em uma cama diante de uma câmera, perguntando se o diretor gosta de suas nádegas, famosa fala de Brigitte Bardot no filme $O$ desprezo, de Jean-Luc Godard. A imagem foi deletada.

O Facebook não informa ao censurado o motivo específico que motivou a retirada de conteúdo ou a suspensão do perfil ou página censurada. Em geral, informa apenas que o texto, imagem ou vídeo violou alguma regra da "Política de uso de dados" ou dos "Padrões da comunidade do Facebook", documentos formulados pelos gestores da rede.

\section{Confiança e entrega de dados pessoais}

Catherine Dwyer, Starr Roxanne Hiltz e Katia Passerini (2007) no artigo intitulado "Trust and privacy concern within social networking sites: a comparison of Facebook and MySpace", trabalharam a relação entre confiança e privacidade nas redes sociais. Trouxeram importantes referências para a análise da entrega voluntária de informações pessoais para as plataformas de relacionamento. Milhões de pessoas, de todos os continentes, atualmente participam de redes sociais on-line, adicionando perfis que revelam abertamente suas informações pessoais.

A reputação das plataformas de relacionamento social on-line, apesar de ter se reduzido devido a uma série de incidentes divulgados pela mídia, se mantém alta. Dwyer, Hitz e Passerini (2007) perguntaram se seria possível participar de uma rede com milhões de pessoas e ser capaz de confiar em todas elas. Aquilo que as pessoas publicam abertamente demonstraria uma confiança nas redes sociais? A privacidade nessas plataformas de relacionamento muitas 
vezes não é a esperada por seus usuários ou não pode ser aferida, o que gera um sentimento de incerteza. Além disso, as informações que os usuários dessas redes sociais geram e que não são públicas são visíveis para os controladores e donos das plataformas que as armazenam e as classificam para diversos usos.

A confiança pode ser definida como a expectativa de uma pessoa em relação a outra de que esta irá executar uma determinada ação ou de que terá um determinado comportamento, esperado por aquele que confia. A confiança, nessa concepção, seria independente da capacidade de monitorar ou controlar a outra parte. Dwyer, Hitz e Passerini (2007) indicam que, em relacionamentos face a face, o compartilhamento de informações críticas e pessoais é determinante para o fortalecimento da confiança. No caso das interações on-line, a confiança também é fundamental.

A confiança é um componente central do relacionamento social em geral e da ideia de legitimidade nos processos políticos. Pode ser vista como uma troca social. Se for percebida como benéfica, provavelmente, ela ocorrerá. Dwyer, Hitz e Passerini (2007) afirmam que a confiança se estrutura conforme certo cálculo de custo percebido. Desse modo, é provável que a confiança seja uma condição prévia para a autorrevelação diante de um baixo risco de perigo percebido.

O Facebook conquistou um nível elevado de reputação ou disseminou a percepção de que os dados e as interações que as pessoas realizam em sua plataforma são inofensivos e que em pouco ou em nada podem prejudicar suas vidas. Essa percepção implica um alto grau de confiança dos usuários da rede social, sendo a base da grande legitimidade que seus gestores possuem para praticar ações de bloqueio, censura e remoção de conteúdos postados.

\section{Privacidade e modulação de comportamentos}

Como organização privada criada e mantida na internet, o Facebook segue a tradição de publicar suas normas de funcionamento e termos de uso. Dois documentos são fundamentais para compreendermos como a plataforma lida com a privacidade e a liberdade de expressão dos cidadãos dos diversos países: a "Política de uso de dados" e os "Padrões da comunidade do Facebook".

A "Política de uso de dados" da rede social teve sua última revisão realizada em 11 de dezembro de 2012. Ela define como o Facebook utiliza os dados coletados das pessoas que acessam a plataforma. Cada vez que alguém inscrito na rede social navega no seu interior gera um registro de cada movimento que realizou, chamado de $\log$, no jargão técnico. Esses registros são informações fundamentais para a formulação de estatísticas de uso da plataforma, mas também permitem construir perfis comportamentais e acompanhar cada click dado e letra digitada por um determinado usuário enquanto esteve visitando o Facebook. Nesse sentido, a "Política de uso de dados" é um elemento fundamental para entender a visão que os gestores do Facebook têm sobre a privacidade e como afirmam garanti-la.

Foram selecionados alguns trechos relevantes do documento com o objetivo de avaliar a relação entre os dados coletados e a consequência dessa coleta para a privacidade existente. Antes, é importante deixar claro que a privacidade pode ser entendida como uma condição social relativa à possibilidade de um indivíduo ter fatos e informações sobre sua vida, 
preferências e comportamentos que não sejam comunicados ou não sejam conhecidos por outros indivíduos. Ela depende de costumes, de fatores sociais e intersubjetivos. A privacidade não pode ser entendida como algo que exista ou não em um único modo. Nas sociedades ocidentais, a ideia de privacidade foi se consolidando em leis e pode ser mais bem compreendida em níveis ou em graus. Os cidadãos de um país podem ter um nível maior de proteção de sua intimidade e de suas informações do que os de outro país.

Presente no artigo "The right to privacy", de Warren e Brandeis (1890), a noção de privacidade ganhou espaço em importantes declarações internacionais tais como a Declaração Universal dos Direitos do Homem, aprovada pela Assembleia Geral das Nações Unidas (1948) e a Carta dos Direitos Fundamentais da União Europeia (2000). Com a expansão das redes informacionais, a questão da privacidade adquire uma nova relevância, uma vez que a comunicação pela internet deixa rastros digitais que permitem identificar e reduzir o nível de privacidade dos comunicadores (Galloway, 2004, p.244).

Quando uma pessoa utiliza o Facebook, ela deixa para os bancos de dados da plataforma não somente os posts que escreveu ou as fotos e vídeos que publicou. O Facebook passa a arquivar os indicadores do comportamento de seus usuários. Na sua política de uso de dados, a empresa esclarece:

Recebemos dados sobre você sempre que interage com o Facebook, como quando você olha a linha do tempo de outra pessoa, envia ou recebe mensagens, procura um amigo ou uma página, clica em, visualiza ou interage de outra forma com as coisas, usa um aplicativo móvel do Facebook, compra Créditos do Facebook ou faz outras compras pelo Facebook. ... Quando você publica algo como fotos ou vídeos no Facebook, podemos receber dados (ou metadados) adicionais relacionados, como hora, data e local em que a foto ou o vídeo foram gravados (Política de uso..., s.d.).

Toda a movimentação realizada pelos usuários é registrada. O tempo que cada pessoa ficou em cada página, os links que a levaram para outros perfis, o padrão de uso das mensagens privadas, os perfis com que o usuário mais se relaciona, os tipos de link patrocinados que atraem sua atenção, entre outros dados. O processamento dessas informações gera o perfil de comportamento de cada pessoa que participa do Facebook, permite organizar melhor os links que serão dispostos na primeira página de cada usuário, ou seja, dá à empresa maior capacidade de venda de publicidade dirigida.

O trabalho de mineração e cruzamento de dados permite descobrir correlações não imaginadas e identificar padrões de comportamento, além de fornecer à corporação a possibilidade de agrupar seus usuários pelos diversos tipos comportamentais, por estilos de potenciais consumidores, por proximidade de interesses, enfim, a partir de diversos recortes. Atualmente, o poder de análise do Facebook é superado somente pelo poder de análise do Google. Poucas corporações privadas hoje em dia têm tamanha capacidade de coletar, processar, minerar e analisar as informações de milhões de pessoas no planeta.

Nós recebemos dados do computador, do telefone celular ou outros dispositivos que você usa para acessar o Facebook, incluindo quando diversos usuários conectam-se através do mesmo dispositivo. Isso pode incluir seu endereço IP e outras informações sobre coisas como seu serviço de internet, localização, o tipo (incluindo identificadores) de navegador que você usa, ou as páginas que você visita. ... Por exemplo, podemos 
obter sua localização no GPS ou outras informações de localização para que possamos informar se algum de seus amigos está próximo de você (Política de uso..., s.d.).

Acessar o Facebook é entregar aos gestores da plataforma sua localização geográfica e até o tipo de computador, tablet ou celular que se está utilizando. Seu deslocamento nos logradouros da cidade fica registrado nos bancos de dados da corporação. São informações valiosas, seja para a vigilância, seja para o que Deleuze (1992a) classificou de controle ou, mais precisamente, para o que aqui denominamos de modulação de comportamento.

A modulação é diferente da vigilância. Deleuze (1992b, p.221) percebeu que "os confinamentos são moldes, distintas moldagens, mas os controles são uma modulação, como uma moldagem autodeformante que mudasse continuamente, a cada instante, ou como uma peneira cujas malhas mudassem de um ponto a outro". Modular é interferir sutilmente no rumo do actante em ação. É conduzi-lo conforme ele avança em seu caminho a aumentar ou reduzir sua velocidade, é induzi-lo à direita ou à esquerda, é chamar sua atenção para a necessidade de uma parada, é trabalhar para reforçar seus gostos e estilos, desde que eles sejam os pretendidos e delimitados pela plataforma de rede e seus investidores e contratantes.

Os dados coletados de milhões de pessoas constituem a mais importante fonte de valor nessa fase da sociedade em rede que viabiliza a sociedade de controle por modulação. Sem esses dados não seria possível modular as necessidades nem criar novas demandas que possam ser rapidamente captadas pelas corporações pagantes da plataforma. A modulação nas redes sociais é claramente observável pelos cliques, curtidas, compartilhamentos e compras on-line que os usuários efetivam. Mas as modulações não são ondas apenas comerciais, incitadoras de consumo, são também morais e políticas. A própria plataforma da rede social também é moduladora do texto e da imagem a ser postada. O Facebook é uma plataforma de modulação que organiza e enquadra os nossos discursos e práticas em sua arquitetura e design, enfim, ele pratica um controle modular pela interface e uma modulação forte pelo processamento dos dados dos seus usuários.

O Facebook mescla ações disciplinares e controle modular, uma espécie de biopolítica que se faz em rede e pela rede, transnacional, não praticada pelo Estado, mas a favor de alguns deles. Os "Padrões da comunidade do Facebook" e os denominados "Princípios do Facebook" são práticas discursivas da rede que descrevem o que os donos e gestores da plataforma definem como o cuidado que devem ter com as pessoas e empresas que a utilizam. Veremos como as pessoas possuem graus de liberdade modulada dentro do Facebook.

\section{Discussões públicas e censura privada}

No cenário da tecnologia, a expressão "jardim murado" (Arthur, 17 abr. 2012) é utilizada para caracterizar algo que é fechado, cercado, com acesso restrito, sendo o oposto das plataformas abertas. A internet é apresentada como um grande exemplo de tecnologia aberta, universalizante, não proprietária e sem um centro controlador. O Facebook é um exemplo de "jardim murado". Para acessar o conteúdo que nele foi inserido é preciso ser aceito na sua plataforma, concordar com seus termos de utilização e abrir um perfil. O modo como foi desenhada a arquitetura da internet, uma rede distribuída sem controle central, impede que 
alguém possa ser banido da internet. Também assegura que possamos criar novos conteúdos, aplicações e soluções sem a necessidade de que algum órgão os aprove. O Facebook pode expulsar, desligar ou suspender qualquer um de seus membros, pois é uma rede que exige uma senha para um identificador e uma senha para entrar. Sua arquitetura é centralizada, e toda a criação de soluções em seu interior depende de autorização prévia dos seus gestores.

Como um grande "jardim murado", o Facebook anulou uma das principais características que os filósofos suecos Alexander Bard e Jan Söderqvist (citados em Ugarte, 2008, p.26) afirmam encontrar em redes distribuídas como a internet, a saber, "todo ator individual decide sobre si mesmo, mas carece da capacidade e da oportunidade para decidir sobre qualquer dos demais atores". Por exemplo, o governo dos Estados Unidos ordenou que o provedor de acesso Amazon retirasse o site do Wikileaks da internet. Como resposta, os ciberativistas imediatamente subiram em diversos servidores nos cinco continentes mais de oitocentos sites espelhos, ou seja, idênticos ao que tinha sido bloqueado (Twitter e..., 21 mar. 2013). Assim, nem o poderoso governo norte-americano foi capaz de remover o site do Wikileaks de uma rede distribuída. Já o Facebook consegue, com facilidade, desabilitar perfis identificados como problemáticos, uma vez que controla todos os computadores-servidores de sua plataforma.

Em janeiro de 2013, foi denunciada mais uma forte intervenção do Facebook no posicionamento de seus usuários. Os gestores da rede proibiram a inserção das palavras Guarani-Kaiowá nos perfis dos membros da plataforma que estavam denunciando o massacre dos índios na região central do Brasil. Para apoiar a causa indígena, internautas incluíam o nome da etnia em seus sobrenomes. Sem prestar nenhuma explicação, o Facebook passou a impedir esse uso nos perfis, bloqueando os usuários que não se subordinavam ao seu mando (Facebook impede..., 11 jan. 2013). Como rede social privada, voltada ao entretenimento, o Facebook não se vê obrigado a aceitar em sua plataforma as liberdades fundamentais que constituíram as democracias liberais.

A estrutura, as interfaces e as regras das redes de relacionamento social são definidas pelos seus administradores, buscando estar em consonância com os interesses de seus investidores. Em geral, as chamadas redes sociais são plataformas remuneradas por acessos, venda de publicidade, links patrocinados e propaganda dirigida para microaudiências que podem ser identificadas pelos robôs e analistas de comportamento de usuários. Os bloqueios e a remoção de conteúdos não se baseiam em preceitos constitucionais, uma vez que são plataformas privadas. Sem dúvida, os diversos Estados nacionais atuam sobre essas redes para fazer valerem suas legislações, tanto que, desde 2012, o Twitter utiliza uma tecnologia que permite censurar mensagens divulgadas no nanoblogger apenas nos países em que elas são proibidas (Twitter cria..., 27 jan. 2012). Todavia, Facebook e Twitter não bloqueiam conteúdos, suspendem ou removem perfis apenas por determinação da Justiça. Atuam conforme seus termos de uso e regras de negócios. Esses documentos não são votados por parlamentos nem seguem uma Constituição, por isso, mudam constantemente, conforme os interesses de seus controladores.

O fotógrafo Fernando Rabelo escreveu no blog da Associação Mucury Cultural, integrante da rede Fora do Eixo, a seguinte denúncia: "O meu mural de fotografias históricas é mais uma vez censurado pelo Facebook, que me puniu com três dias de suspensão a partir de hoje (15 mar.). Desta vez uma fotografia publicada no ano passado, a da filósofa existencialista e ícone feminista Simone de Beauvoir nua de costas em um banheiro, foi removida do site 
(Facebook censura..., 15 mar. 2013). Esse exemplo demonstra que uma foto divulgada na revista francesa Le Nouvel Observateur e em outros sites e publicações, embora não tenha sido contestada judicialmente, foi censurada pelos critérios da rede de relacionamento social. $\mathrm{O}$ poder de fixar o padrão de relacionamento de uma rede e de excluir aqueles que o estariam de alguma forma violando é chamado por Manuel Castells (2009) de poder de conectar em rede (networking power). No caso, o Facebook possui critérios de aplicação de sua política de remoção de conteúdos que castiga a nudez. Em muitos outros casos, a remoção realizada pelos administradores da plataforma foge da compreensão dos punidos e excluídos, uma vez que elas não são claras e diferem das exigências legais do país em que o conteúdo foi publicado.

Apesar de dificilmente serem consideradas expressões de pornografia, já foram removidas fotos de mães amamentando seus filhos, feministas protestando com seus seios descobertos, como ocorreu com fotos da "Marcha da Vadias" ou com o bloqueio de perfis que fotografaram militantes com vestidos transparentes no "Existe amor em SP", bem como, o despretensioso evento ocorrido em Curitiba, no qual amigos do ciclista Nelson Rabello tiraram uma foto em que aparecem de sunga (imagens de artistas de sunga são expostas em horário nobre da televisão brasileira sem despertar nenhuma resistência relevante na opinião pública brasileira).

Esses casos de maior repercussão, entre tantos outros ocorridos em diversos países, demonstram uma ação arbitrária praticada pelo Facebook que nem sempre segue as próprias regras e quase nunca diz ao censurado quais regras ele violou, conformando uma verdadeira situação kafkaniana, em que não é possível afirmar a inocência, pois não é sabido extamente qual a acusação. O fato é que, para os gestores do Facebook, eles estão administrando um negócio privado, não um país com governantes eleitos e com leis aprovadas pelos representantes do povo. Uma pessoa é obrigada a seguir a Constituição do seu país, mesmo que não goste. Ninguém é obrigado a participar do Facebook. Devido a esse argumento, a maior rede social do planeta não se sente obrigada a dar satisfação de sua dinâmica e de suas decisões para quem não seja seu investidor.

Entretanto, em abril de 2015, o Facebook recuou e desbloqueou uma foto que havia sido censurada na página que o Ministério da Cultura do Brasil mantém naquela plataforma. Uma índia com seios aparentes em um retrato dos índios botocudos feito por Walter Garbe, em 1909, foi removida pelos gestores da rede social. A foto censurada é similar a outras que integram diversos materiais didáticos do ensino fundamental brasileiro. Como resposta, o ministro da Cultura, Juca Ferreira, anunciou que processaria o Facebook por cerceamento da liberdade de expressão. Imediatamente, a rede recuou e sua assessoria de imprensa soltou uma nota em que afirmou respeitar "leis locais e, assim como qualquer outra mídia, temos limitações com nudez. Estamos sempre abertos a feedback e ao debate para melhorar nossos Padrões da Comunidade" (Pessoa, 17 abr. 2015). Todavia, recuos dos gestores do Facebook não ocorreram em outros casos aqui relatados.

Como plataforma privada, controlada por acionistas, sediada em um país cujo Estado pratica a exceção como regra diante das supostas ameaças de terrorismo, o Facebook também é um espaço virtual em que ocorrem as interações críticas e conversações dos cidadãos sobre sua vida cotidiana e sobre a política. Esse é o problema crucial deste artigo. Sendo um espaço virtual privado, o Facebook se diferencia dos sites dos governos. Também 
se distingue de uma plataforma de comércio eletrônico, já que a venda de produtos on-line não é a prática central da rede social. O Facebook afirma criar regras próprias, mas, devido a sua localização originária, deve estar em consonância com o aparato legal norte-americano, sem necessariamente estar em conformidade com o ordenamento jurídico dos países em que vivem seus usuários.

Consolidado como espaço virtual de debates e articulações políticas e culturais, o Facebook se tornou um importante componente da esfera pública. Como organização privada e lócus onde ocorrem os debates, as regras de conduta em vigor expressam a estética e a moral dos seus administradores e acionistas. O Facebook é um jardim murado. Dentro de seus limites, as regras de conduta e de liberdade política valem até o momento em que não contrariem interesses comerciais, alianças estratégicas, determinações do departamento de Estado norte-americano e a perspectiva de crescimento de usuários estipulada por seus administradores.

Redes sociais fechadas, privadas, lembram muito o modo como Giorgio Agamben (2004, p.78) definiu a atual situação dos Estados nacionais como estados de exceção: "O estado de exceção não é uma ditadura (constitucional ou inconstitucional, comissária ou soberana), mas um espaço vazio de direito, uma zona de anomia em que todas as determinações jurídicas - e, antes de tudo, a própria distinção entre público e privado - estão desativadas". Redes sociais, como o Facebook, são híbridas. Elas são comandadas pelos interesses de seus donos, mas nelas estão ocorrendo as conversas que formam a opinião pública. O Facebook é uma rede privada, transnacional, de origem norte-americana, mas que possui a maior parte dos cidadãos conectados de outros países debatendo seu cotidiano e suas relações de poder, conformando um espaço tipicamente público.

Há algum tempo, pensadores como Stuart Hall (1992) haviam mostrado que a modernidade tardia havia trazido inúmeras dificuldades para as divisões simétricas e claramente delimitadas erguidas no mundo industrial, entre as quais, a separação entre o público e o privado. Portanto, as redes de relacionamento social on-line, entre elas o Facebook, podem ser enquadradas como mais um exemplo dessa indistinção entre o que é estritamente privado e o que é claramente público. A questão fundamental é se um espaço privado, em que ocorrem importantes debates públicos, pode estar submetido apenas ao controle de seu proprietário. Dito de outro modo: nesses espaços privados devem prevalecer as determinações constitucionais que asseguram as liberdades tão fundamentais à esfera pública? Devemos pensar em novos estatutos para os espaços híbridos?

O liberalismo pensou as garantias dos indivíduos contra os abusos do poder do Estado. A censura praticada pelo Estado passou a ser entendida como algo inceitável para as democracias liberais. Todavia, o cenário aqui apresentado é diferente. Não é o Estado que está cerceando determinadas manifestações políticas e expressões criativas, mas o dono do empreendimento privado que reúne a maioria da população adulta do país. Trata-se de uma censura definida pelo dono do "jardim murado", aqui denominada de censura privada ou censura da esfera híbrida.

Aqui o liberalismo fracassa, não sabendo escolher entre a livre iniciativa e a liberdade de expressão. A restrição à liberdade dos investidores e gestores da plataforma seria um atentado 
à liberdade de negócios tão importante ao liberalismo, mas ela é indispensável para garantir que seus usuários tenham suas opiniões respeitadas e não excluídas da rede de relacionamento social privada. Enquanto não se enfrenta o problema social dos espaços híbridos, a censura dos gestores da corporação é efetuada e legitimada pelo argumento do tipo "os incomodados que se mudem", ou seja, ninguém é obrigado a acessar uma rede de relacionamento social on-line.

\section{Considerações finais sobre censura e bioestética de modulação}

A liberdade de criação artística integra a liberdade de expressão. Trata-se de um dos direitos fundamentais que compõe as liberdades básicas, tão caras às doutrinas que vão do liberalismo até as democracias radicais. A pesquisa aqui realizada aponta que a maioria dos dez casos de censura praticada pelos administradores do Facebook tratava de bloquear imagens de nudez. Tal procedimento parece originar-se em uma estética com a finalidade de condução ou de modulação dos indivíduos conectados conforme uma perspectiva de vida conservadora. Simultaneamente, a plataforma de relacionamento se esforça para ser identificada com as mais radicais inovações tecnológicas, expressões de um progresso advindo da crença de uma neutralidade totalizante e positiva inerente ao mundo da técnica. Para refletir sobre tal situação, é prudente ouvirmos Peter Pál Pelbart (2011, p.58): “a sexualidade encontra-se precisamente nesse entrecruzamento entre os dois eixos da tecnologia política da vida, a do indivíduo e da espécie, a do adestramento dos corpos e a regulação das populações, a dos controles infinitesimais, o micropoder sobre os corpos e as medidas massivas, estimações estatísticas, intervenções que visam ao corpo social como um todo".

Toda nudez será castigada nas páginas do Facebook. Mesmo sendo não pornográfica, artística, histórica, antropológica, científica, a nudez lembra a sexualidade e por isso não pode ser tolerada na rede social. Como foi possível observar, essa estética para a organização social transnacional guarda uma perspectiva de modulação ética. Ela não visa à punição do adolescente que postou sua foto nu ou do jornal que publicou imagens das manifestantes sem roupa, ela pretende levá-los a aceitar um padrão de comunicação do qual a nudez não deve fazer parte. Trata-se de uma bioestética.

Uma estética sobre a vida remete a uma ética, a um modo de viver e de se comportar. A noção de biopolítica trazida por Foucault (1984, 2000a, 2000b) para falar sobre o controle da espécie, de uma modelagem das populações para além da disciplina dos corpos, aqui é pensada como um controle das interações em rede que extrapolam o território e perpassam as diversas culturas. Os gestores da plataforma criam um mundo regrado e esteticamente pensado conforme a visão de mundo que buscam defender. A estética do Facebook também é uma política sobre a vida dentro da plataforma, portanto, uma política de controle de todos, uma biopolítica da espécie em rede.

Atualmente, não existe nenhum outro local onde se reúnam tantas pessoas simultaneamente discutindo os rumos do "mundo da vida", no sentido habermasiano, e a política no sentido local e global, como nas redes sociais on-line. Um comício ou convenção de um partido pode contar com a presença de pessoas com laços mais fortes entre si, mas dificilmente superará em número de pessoas envolvidas nas conversações sobre questões públicas no Facebook ou no Twitter. 
A intensificação da interatividade comunicativa não deve perder força nos próximos anos, ela deve avançar mesmo nos processos de convergência digital. A interatividade em rede permite e facilita a elaboração de plataformas de interação, de troca, de crítica, enfim, de relacionamento político, por isso, as chamadas redes de relacionamento social são decisivas nas conversações que formam a opinião pública.

Os espaços e esferas públicas de baixa interatividade são pressionados pela tendência geral de alta interatividade e de grande relacionamento. É perceptível que os governos não construíram esses processos interativos, pois se encastelaram nos processos baseados em representantes e se preocuparam em consolidar sistemas políticos fundados em camadas de representação. As democracias são de baixa interatividade, pequeno grau de participação, poucos processos de deliberação.

O surgimento dos blogs intensificou as interações políticas e reanimou a esfera pública, trazendo novos atores desprovidos de grandes recursos e de aparatos logísticos.

As redes sociais consolidaram plataformas de relacionamento, principalmente voltadas para o entretenimento e a conversação. Pelo seu grande e rápido sucesso, essas plataformas privadas se tornaram terrenos de debates políticos e de posicionamentos públicos fundamentais. Não são concessões públicas, não dependem de autorização para existir, são transnacionais, partem da língua inglesa para ser globais e se mantêm como estruturas privadas.

Tais plataformas privadas de relacionamento público são fundamentais nos debates públicos e na formação de uma ideia pública. Mais do que isso, aparentam ser elementos de conformação bioestética, ou seja, de uma estética de dominação dos ciberviventes que é ao mesmo tempo uma estética de modulação, em que os equilíbrios mentais e afetivos são formados. Essas redes de relacionamento, então, são plataformas distribuídas de controle do debate. Controle entendido principalmente como modulação, mas também como vigilância e possibilidade de censura.

Por fim, essas plataformas privadas se ergueram como um dos componentes mais importantes dos debates públicos. Contraditoriamente, uma plataforma privada segue as regras dos seus donos. Assim como uma casa de debates liberais não é obrigada a convidar socialistas para debater, as plataformas privadas de conversas públicas não estão obrigadas a seguir lógicas políticas de equidade de espaço para as forças políticas, muito menos devem seguir regras constitucionais de liberdade de opinião. Aqui encontramos o múltiplo contraditório das redes híbridas, entre o público, o comum e o privado.

\section{AGRADECIMENTOS}

Este artigo é baseado em pesquisa apresentada no Seminário Temático de Ciberpolítica, Ciberativismo e Cibercultura da Associação Nacional de Pós-graduação e Pesquisa em Ciências Sociais (Anpocs), em 2013, realizada por Elaine Ortiz e por mim (Ortiz, Silveira 2013).

\section{REFERÊNCIAS}

AGAMBEN, Giorgio.

Estado de exceção. São Paulo: Boitempo. 2004.

ALEXA.

Alexa. Disponível em: http://www.alexa.com/ topsites. Acesso em: 30 abr. 2013. s.d.
ARBITRARY...

Arbitrary and capricious. The Economist. Disponível em:http://www.economist.com/ blogs/democracyinamerica/2014/08/facebookcensorship. Acesso em: 12 fev. 2015. 28 ago. 2014. 
ARTHUR, Charles.

Battle for the internet (Part 3 of series): Walled gardens look rosy for Facebook, Apple: and would-be censors. The Guardian. Disponível em: http://www.theguardian.com/technology/2012/ apr/17/walled-gardens-facebook-apple-censors. Acesso em: 10 fev. 2015. 17 abr. 2012.

BENKLER, Yochai.

The wealth of networks: how social production transforms markets and freedom. New Haven: Yale University Press. 2006.

BRUNO, Cássio.

Facebook admite que apagou post de Dilma Bolada sobre Aécio Neves. O Globo. Disponível em: http://oglobo.globo.com/brasil/facebookadmite-que-apagou-post-de-dilma-bolada-sobreaecio-neves-8539996. Acesso em: 20 jun. 2013. 29 maio 2013.

CASTELLS, Manuel.

Comunicación y poder. Madrid: Alianza. 2009.

CETIC-CGI.

Centro Regional de Estudos para o

Desenvolvimento da Sociedade de InformaçãoComitê Gestor da Internet. TIC Domicílios e Empresas: pesquisa sobre o uso das tecnologias de informação e comunicação no Brasil (livro eletrônico). São Paulo: Comitê Gestor da Internet no Brasil. Disponível em: http://cetic.br/ pesquisa/domicilios/indicadores. Acesso em: 20 jun. 2014. 2013.

DELEUZE, Gilles.

Controle e devir. In: Deleuze, Gilles. Conversações. São Paulo: Editora 34. p.209-218. 1992a.

DELEUZE, Gilles.

Post-scriptum: sobre as sociedades de controle. In: Deleuze, Gilles. Conversações. São Paulo: Editora 34. p.219-226. 1992b.

DWYER, Catherine; HILTZ, Starr Roxanne; PASSERINI, Katia.

Trust and privacy concern within social networking sites: a comparison of Facebook and MySpace. In: Americas' Conference on Information Systems, 13., 2007, Keystone. Proceedings, paper n.339. Disponível em: http://aisel.aisnet.org/amcis2007/339. Acesso em: 20 jun. 2014. 2007.

EM DOIS ANOS..

Em dois anos, Facebook no Brasil atinge a marca de 67 milhões de usuários. Portal da Imprensa. Disponível em: http://portalimprensa.com.br/ noticias/brasil/57480/. Acesso em: 30 abr. 2013. 20 mar. 2013.

FACEBOOK CENSURA...

Facebook censura foto da ícone feminista Simone de Beauvoir. Portal Fora do Eixo. Disponível em: http://foradoeixo.org.br/mucurycultural/ blog/facebook-censura-foto-da-icone-feministasimone-de-beauvoir. Acesso em: 10 jun. 2013. 15 mar. 2013.

\section{FACEBOOK IMPEDE...}

Facebook impede que usuários mudem nome para "Guarani-Kaiowá". Portal G1. Disponível em: http://g1.globo.com/tecnologia/ noticia/2013/01/facebook-impede-que-usuariosmudem-nome-para-guarani-kaiowa.html. Acesso em: 15 mar. 2013. 11 jan. 2013.

FOUCAULT, Michel.

Em defesa da sociedade. São Paulo: Martins Fontes. 2000a.

FOUCAULT, Michel.

Vigiar e punir: história da violência nas prisões. Petrópolis: Vozes. 2000b.

\section{FOUCAULT, Michel}

História da sexualidade, 1: a vontade de saber. Rio de Janeiro: Graal. 1984.

GALLOWAY, Alexander.

Protocol: how control exists after decentralization. Cambridge: The MIT Press. 2004.

HABERMAS, Jürgen.

Direito e democracia: entre facticidade e validade. v.2. Rio de Janeiro: Tempo Brasileiro. 1997.

HALL, Stuart.

A identidade cultural na pós-modernidade. Rio de Janeiro: DP\&A. 1992.

ORTIZ, Elaine; SILVEIRA, Sergio Amadeu. Redes sociais, censura privada e modulação. In: Encontro Anual da Anpocs, 37., 2013, Águas de Lindoia. Anais. Disponível em: http://portal.anpocs.org/portal/index. php?option $=$ com_docman\&task $=$ doc details\&gid $=8579 \&$ Itemid $=429$. Acesso em: 20 jun. 2014. 2013.

PADRÕES...

Padrões da comunidade do Facebook. Facebook. Disponível em: https://www.facebook.com/ communitystandards/. Acesso em: 4 ago. 2013. s.d.

PELBART, Peter Pál.

Vida capital: ensaios de biopolítica. São Paulo: Iluminuras. 2011.

PESSOA, Gabriela Sá.

Após ministério ameaçar processo, Facebook republica foto censurada. Folha de S.Paulo. Disponível em: http://www1.folha.uol.com.br/ ilustrada/2015/04/1618154-minc-diz-que-iraprocessar-facebook-apos-foto-censurada-de-casalde-indios.shtml. Acesso em: 18 abr. 2015. 17 abr. 2015. 
POLÍTICA DE USO...

Política de uso de dados. Facebook. Disponível em: https://www.facebook.com/full_data_use_ polic. Acesso em: 4 ago. 2013. s.d.

\section{PRINCÍPIOS...}

Princípios do Facebook. Facebook. Disponível em: https://www.facebook.com/principles.php. Acesso em: 4 ago. 2013. s.d.

TWITTER CRIA...

Twitter cria sistema para censurar mensagens por país. Revista Época. On-line. Disponível em: http://colunas.revistaepoca.globo.com/ ofiltro/2012/01/27/twitter-cria-sistema-paracensurar-mensagens-por-pais/. Acesso em: 1 maio 2013. 27 jan. 2012.
TWITTER E...

Twitter e Facebook estão sob o controle de Washington, diz Julian Assange. Portal Imprensa. Disponível em:

http://portalimprensa.uol.com.br/noticias/ internacional $/ 57521 /$ twitter+e+facebook+estao+s $\mathrm{ob}+\mathrm{o}+$ controle+de+washington+diz+julian+assan ge. Acesso em: 10 jun. 2014. 21 mar. 2013.

UGARTE, David.

O poder das redes. Porto Alegre: EdiPUCRS. 2008.

WARREN, Samuel; BRANDEIS, Louis.

The right to privacy. Harvard Law Review, v.4, n.5. Disponível em: http://groups.csail.mit.edu/mac/ classes/6.805/articles/privacy/Privacy_brand_ warr2.html. Acesso em: 8 out. 2015. 1890. 